\title{
Effect of Surface Asperity on Diffusion Bonding
}

\author{
Airu Wang ${ }^{1, *}$, Osamu Ohashi ${ }^{2}$ and Kenji Ueno ${ }^{3}$ \\ ${ }^{1}$ Venture Business Laboratory, Niigata University, Niigata 950-2181, Japan \\ ${ }^{2}$ Graduate School of Science and Technology, Niigata University, Niigata 950-2181, Japan \\ ${ }^{3}$ High Energy Accelerator Research Organization, Tsukuba 305-0801, Japan
}

\begin{abstract}
The effect of surface asperity (mainly ridge height $H$, ridge wavelength $W$ and aspect ratio $H / W$ ) on the diffusion bonding process was investigated. Ridge wavelength $W$ as well as ridge height $H$ have a significant effect on the properties of the diffusion bonded joint. The percent of bonded area increased with decreases in $W$ and $H$. When the ridge height $H$ was constant, an increase in aspect ratio $H / W$ accelerated atomic diffusion at void surfaces and bonding interfaces, facilitated void shrinking and increased the bonded area. This can improve the strength of diffusion bonded joints. The percent of bonded area can be predicted by numerical analysis for surfaces prepared by lathe machining.
\end{abstract}

(Received October 4, 2005; Accepted November 21, 2005; Published January 15, 2006)

Keywords: diffusion bonding, surface asperity, ridge wavelength, percent of bonded area

\section{Introduction}

Diffusion bonding is an attractive joining technique for the manufacture of precision apparatus and complex structures because bonding is performed without a fusion process. The bonded joints have the strength of parent materials and high dimensional stability. In general, diffusion bonding temperatures are in the range of $0.5-0.8 T_{\mathrm{m}}$, where $T_{\mathrm{m}}$ is the absolute melting point of the bonded materials. However, deformation and grain growth occur in joints bonded at such elevated temperatures, which can create significant problems. The lowest possible bonding temperature is desirable to produce high quality diffusion-bonded joints.

There are two ways to lower the bonding temperature. One is cleaning the faying surface. It has been shown that oxide films on a faying surface form inclusions at the bonding interface, and the inclusions degrade the bond. ${ }^{1,2)}$ Ion beam bombardment removes the oxide film on the faying surface, thus lowering the bonding temperature. ${ }^{1-3)}$ Using Ar-beam surface treatment, some joints can be made even at room temperature, e.g. Al foils and $\mathrm{Si}$ wafaers. ${ }^{4,5)}$ The other technique is smoothing the faying surface. Low surface roughness increases the bonded area and improves the strength of the bond accordingly. ${ }^{6}$ )

In order to analyze the bonded area quantitatively, several numerical models were developed. ${ }^{7-12)}$ For pure metals with known specific diffusion and creep data, such as copper $(\mathrm{Cu})$, nickel $(\mathrm{Ni})$, silver $(\mathrm{Ag})$, and titanium $(\mathrm{Ti})$, the diffusionbonded area can be calculated or estimated in advance. For copper specimens with nanometer-scale surface roughness, we have reported that the actual bonded area was consistent with that calculated using a numerical model, and the joints with $100 \%$ bonded area were achieved at low bonding temperatures. ${ }^{13)}$

Surface asperity can be described using three parameters: ridge height $H$, ridge wavelength $W$, and surface waviness. Previous investigations of the effect of surface asperity focused mainly on surface roughness (maximum height roughness $R_{\mathrm{Z}}$ or arithmetical mean roughness $R_{\mathrm{a}}$ ), in other words only the ridge height $H$ of surface asperity was

*Corresponding author, E-mail: wangairu@gs.niigata-u.ac.jp considered. The effect of ridge wavelength $W$ has not yet been investigated.

In the present study, we investigated the effects of ridge wavelength $W$ as well as ridge height $H$ and aspect ratio $H / W$ on the properties of diffusion bonded joints. The applicability of numerical analysis to surfaces with different surface asperities (surface roughness $R_{\mathrm{Z}}$, ridge height $H$, ridge wavelength $W$, and aspect ratio $H / W$ ) prepared by lathe machining was analyzed. The optimum surface asperity for improved bonding is discussed.

\section{Experimental Methods}

The material used in this study was oxygen-free highconductivity copper (OFHC class 1 ). Its chemical composition is shown in Table 1.

The test specimens were cylinders with a diameter of $12 \mathrm{~mm}$ and a length of $30 \mathrm{~mm}$. The initial surface to be bonded was machined on a lathe. In this study, four kinds of surface asperities with different surface parameters (surface roughness $R_{\mathrm{Z}}$, ridge height $H$, ridge wavelength $W$ ) were prepared by changing the cutting speed and the feed of the tool. The surface of specimen A, which had the least surface roughness, was machined using a natural single-crystal diamond tool, while the surfaces of specimens B, C and D were prepared with a high speed steel tool. Parameters for surface asperities were obtained with a stylus tip type surface roughness tester (Form Talysurf Series 2; Taylor Hobson, Leicester, England).

The specimens were ultrasonically cleaned in acetone for $10 \mathrm{~min}$ and dried in air before diffusion bonding. Each pair of specimens was kept in contact in a high frequency induction heater. In order to restrain the deformation of joints, a bonding pressure of $5.8 \mathrm{MPa}$ was chosen, which is about $1 / 3$ of the yield stress at $700^{\circ} \mathrm{C}$. Diffusion bonding experiments were conducted in a vacuum of $\sim 10^{-4} \mathrm{~Pa}$. The heating rate was $30^{\circ} \mathrm{C} / \mathrm{min}$ to restrain skin effaces during high frequency induction heating. The holding time at bonding temperature was $20 \mathrm{~min}$. An R-type thermocouple, welded at about $1 \mathrm{~mm}$ from the interface, was used to measure the bonding temperature.

Deformation of joints was represented by eq. (1) through 
Table 1 Chemical composition of OFHC class 1 (mass\%).

\begin{tabular}{ccccccccccccccc}
\hline $\mathrm{Cu}$ & $\mathrm{Bi}$ & $\mathrm{Cd}$ & $\mathrm{Pd}$ & $\mathrm{Hg}$ & $\mathrm{O}$ & $\mathrm{P}$ & $\mathrm{Se}$ & $\mathrm{S}$ & $\mathrm{Te}$ & $\mathrm{Zn}$ & \\
\hline $99.996 \%$ & $3 \mathrm{ppm}$ & $<1 \mathrm{ppm}$ & $3 \mathrm{ppm}$ & $<1 \mathrm{ppm}$ & $<3 \mathrm{ppm}$ & $1 \mathrm{ppm}$ & $<2 \mathrm{ppm}$ & $10 \mathrm{ppm}$ & $<1 \mathrm{ppm}$ & $<1 \mathrm{ppm}$ & \\
\hline
\end{tabular}

measuring of cross sectional area before and after diffusion bonding.

$$
D=\frac{S_{2}-S_{1}}{S_{1}} \times 100 \%
$$

Tensile tests of the bonded joint were carried out using an autograph tester (AG-250KNG; Shimadzu Corporation). A tensile velocity of $1 \mathrm{~mm} / \mathrm{min}$ was used.

After the tensile test, the fractured surfaces of joints were examined with an optical microscope (Model ECLIPSEM600P, Nikon, Tokyo, Japan) and a scanning electron microscope (SEM) (Model JSM-6400, JEOL, Tokyo, Japan). The actual percent of bonded area $S$ was determined as follows. First, the optical micrographs were recorded. The percent of bonded zone (A\%) was determined from the optical micrographs using software Dibas32 and Area Meas. Then, SEM micrographs of eight randomly selected area from the bonded zone were recorded at fixed magnification. The small non-bonded sections were measured and the percent of bonded zone $\mathrm{B}_{\mathrm{i}} \%(i=1-8)$ within the zone was estimated from each SEM micrograph. The average $\mathrm{B} \%$ was calculated with equation $\mathrm{B} \%=\left(\mathrm{B}_{1}+\mathrm{B}_{2}+\cdots+\mathrm{B}_{8}\right) / 8$. The product of the $\mathrm{A} \%$ and $\mathrm{B} \%$ was regarded as the actual percent of bonded area.

\section{Results and Discussion}

\subsection{Diffusion bonding for various surfaces}

Surface asperities were measured for four kinds of specimens prepared by different cutting speeds and tool feed rates. Based on ISO4287-1997, the standard length L used was $0.08 \mathrm{~mm}$ for specimen $\mathrm{A}, 0.8 \mathrm{~mm}$ for specimens $\mathrm{B}$ and $\mathrm{C}$, and $2.5 \mathrm{~mm}$ for specimen $\mathrm{D}$. The measured surface profile of specimen $\mathrm{C}$ is shown in Fig. 1. Surface roughness $R_{\mathrm{Z}}$ was defined using the distance from peak tip to nadir within the standard length. The distance from peak to valley is designated ridge height $H$, and the distance between two adjacent peaks is ridge wavelength $W$. Table 2 shows the measured surface asperity parameters for various specimens used in this study. The $H$ shown in Table 2 is an average of all ridge heights within the evaluated length, and $W$ is the average of all ridge wavelengths.

Specimens with various surface asperities were bonded at $200-700^{\circ} \mathrm{C}$ and the tensile properties of the joints were investigated. Figure 2 shows the relationship between tensile strength and bonding temperature for four kinds of specimens. It can be seen that tensile strength increases with decreasing surface roughness $R_{\mathrm{Z}}$. The strength of the parent material, which underwent the same heat history, was 219.5 MPa for a temperature of $300^{\circ} \mathrm{C}$, and $216.5 \mathrm{MPa}$ for $700^{\circ} \mathrm{C}$. For the specimen with a surface roughness of $90 \mathrm{~nm}$, the tensile strength of the joint was equal to the parent strength at $700^{\circ} \mathrm{C}$.

After tensile testing, microstructures on the fractured

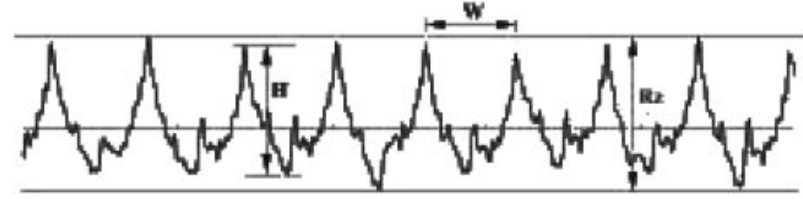

Fig. 1 A typical surface profile measured by a stylus tip type surface roughness tester. $R_{\mathrm{Z}}$ : surface roughness; $H$ : ridge height; $W$ : ridge wavelength.

Table 2 Parameters of surface asperities for various surfaces.

\begin{tabular}{ccccc}
\hline \multirow{2}{*}{ Samples } & \multicolumn{4}{c}{ Surface Parameters } \\
\cline { 2 - 5 } & $R_{\mathrm{Z}}$ & $H$ & $W$ & $H / W$ \\
\hline $\mathrm{A}$ & $90 \mathrm{~nm}$ & $17 \mathrm{~nm}$ & $4.6 \mu \mathrm{m}$ & 0.004 \\
$\mathrm{~B}$ & $1.5 \mu \mathrm{m}$ & $0.9 \mu \mathrm{m}$ & $24 \mu \mathrm{m}$ & 0.04 \\
$\mathrm{C}$ & $4.4 \mu \mathrm{m}$ & $3.6 \mu \mathrm{m}$ & $120 \mu \mathrm{m}$ & 0.03 \\
$\mathrm{D}$ & $14 \mu \mathrm{m}$ & $12 \mu \mathrm{m}$ & $320 \mu \mathrm{m}$ & 0.04 \\
\hline
\end{tabular}

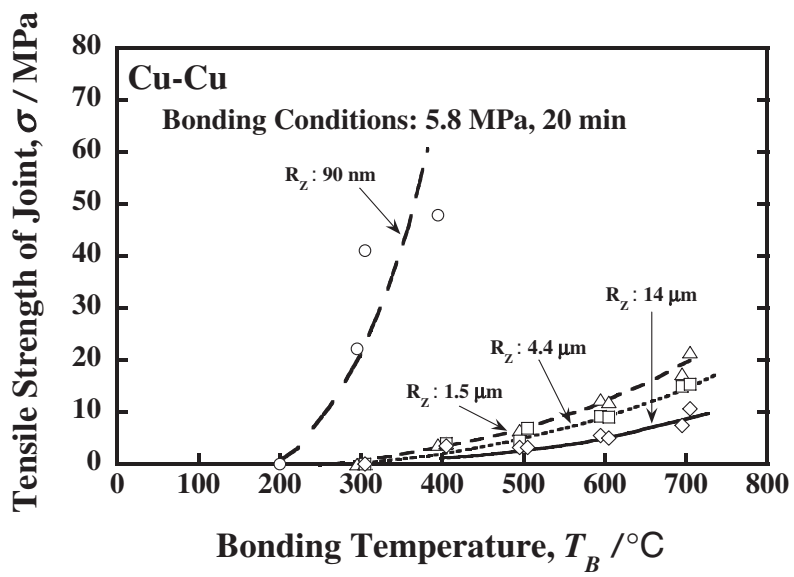

Fig. 2 Relationship between tensile strength of joints and bonding temperature for various surfaces prepared by lathe machining method.

surfaces of the joints were examined with SEM. The distribution of bonded and unbonded areas on the fractured surfaces was investigated. Figures 3(a) and (b) show SEM micrographs of the fractured surfaces for a surface roughness $\left(R_{\mathrm{Z}}\right)$ of $14 \mu \mathrm{m}$ and $90 \mathrm{~nm}$, respectively. Bright zones are bonded areas, with the number of dimples determined by high magnification micrograph. Dark zones are unbonded areas. Almost all unbonded zones are long stria. It is suggested that voids formed on the bonding interface are pipes.

In addition, deformation of the joint during diffusion bonding was measured for all specimens. Figure 4 shows the dependence of joint deformation on bonding temperature for various specimens. The deformation of joints increases with increasing bonding temperature, and it does not depend on 


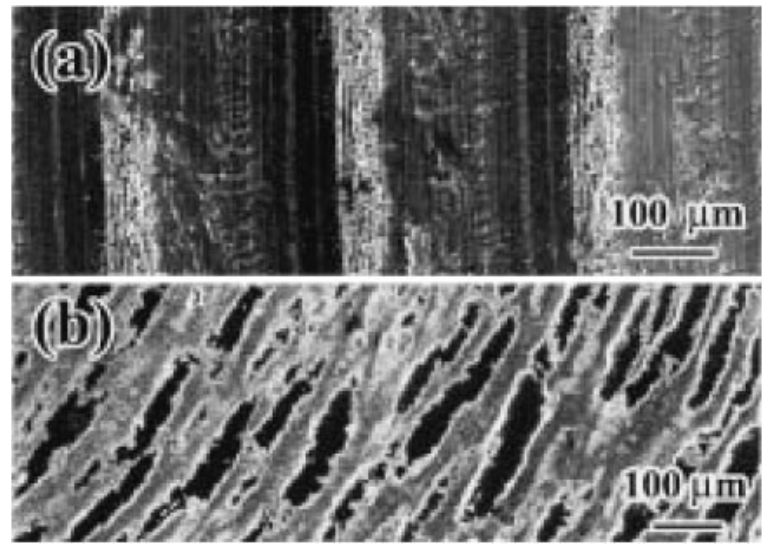

Fig. 3 Microstructures of the fractured surface showing distribution of bonded area. (a) $14 \mu \mathrm{m}, 700^{\circ} \mathrm{C}, 5.8 \mathrm{MPa}, 20 \mathrm{~min}$; (b) $90 \mathrm{~nm}, 400^{\circ} \mathrm{C}$, $5.8 \mathrm{MPa}, 20 \mathrm{~min}$.

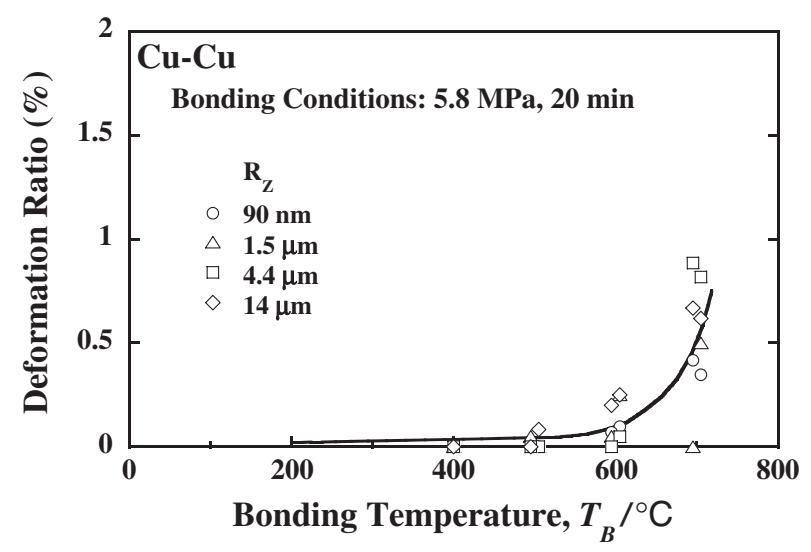

Fig. 4 Relationship between deformation of joints and bonding temperature.

surface roughness. When the bonding temperature is lower than $500^{\circ} \mathrm{C}$, the deformation of joints is slight. Even at $700^{\circ} \mathrm{C}$, which is the highest temperature in this study, the deformation of joints did not exceed $1 \%$.

\subsection{Comparison of calculated and observed percent of bonded area}

A numerical analysis method was developed by Takahashi et al. to evaluate and predict the process of diffusion bonding. ${ }^{10-13)}$ It is proposed that when surfaces with asperities (ridge height $H$, ridge wavelength $W$ ) are bonded by diffusion bonding, the amount of bonded area is controlled by three fundamental mechanisms: plastic deformation, creep deformation and atomic diffusion. Figure 5 shows the numerical analysis model. In this model, the surface profile before bonding is assumed to be a series of triangular ridges, as shown in Fig. 5(a). The long ridges are aligned parallel to each other on each individual surface. Before bonding, the ridges on the two surfaces to be bonded are assumed to lie peak-to-peak, but not peak-to-valley. At the beginning of bonding, plastic deformation occurrs. Bonded areas $S_{P}$ and rhombic voids are formed [as shown in Fig. 5(b)]. $S_{P}$ is calculated based on analysis of the slip lines. With increasing bonding time, creep deformation occurs at the bonding

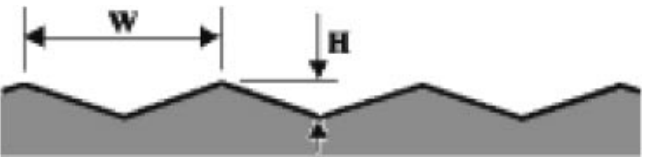

(a)

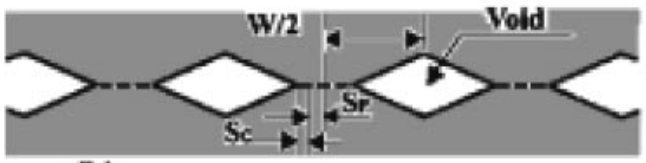

(b)

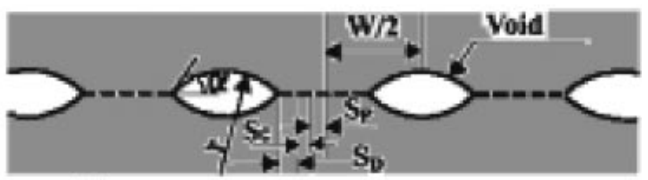

(c)

Fig. 5 A numerical analysis model for diffusion bonding process. ${ }^{10)}$ (a) A triangular ridges model of the faying surface; (b) Initial bonded area $S_{P}$ formed by plastic deformation, and increased bonded area $S_{C}$ resulting from creep deformation; (c) Increased bonded area $S_{D}$ resulting from atomic diffusion.

interface. Creep deformation is modeled as indentation of surface ridges [as shown in Fig. 5(b)] and the increased bonded area resulting from creep deformation is $S_{C}$. Simultaneously, surface diffusion, interface diffusion and volume diffusion occur, resulting from the chemical potential difference between bond-interface and void-surface. A lenticular model [as shown in Fig. 5(c)] is proposed to analyze the contribution of atomic diffusion. The junction between the void-surface and bond-interface is treated as a tip with a dihedral angle $\alpha$. Under the precondition that $\alpha$ remains constant during bonding, the radius of curvature of voids decreases and the voids shrink with $\mathrm{S}_{\mathrm{D}}$. Atomic diffusion is controlled by surface tension $\left(\sigma=\gamma_{\mathrm{S}} / r\right.$, where $\gamma_{\mathrm{S}}$ is surface energy and $r$ is the radius of curvature of voids). From $\sigma=\gamma_{\mathrm{S}} / r$ it is known that voids with small radii (or any regions with a small radius of curvature) show increased atomic diffusion, thus increasing the bonded area. The total bonded area $\mathrm{S}$ comprises contributions from plastic deformation $S_{P}$, creep deformation $S_{C}$ and atomic diffusion $S_{D}$.

Using the obtained parameters (shown in Table 2) and the model program, the percent of bonded area was calculated for four kinds of specimens. The actual percent of bonded area was measured from the SEM micrographs of the fractured surface. Figure 6 compares the actual and the calculated percents of bonded area for specimen $\mathrm{A}\left(R_{\mathrm{Z}}: 90 \mathrm{~nm}\right)$, and Fig. 7 gives the results for other specimens with graeter roughness. Symbols identify the experimental results, and the calculated results are shown by broken lines. It is clear that the calculated results are consistent with the experimental results.

This indicates that the numerical model is suitable for describling diffusion bonding processes over a wide range of specimens, from those machined by a natural single-crystal diamond tool with nanometer scale roughness, to micrometer scale roughness from ordinary lathe machining. Moreover, the numerical model can also be used to predict the diffusion bonding process for those conditions with pipe-like voids in 


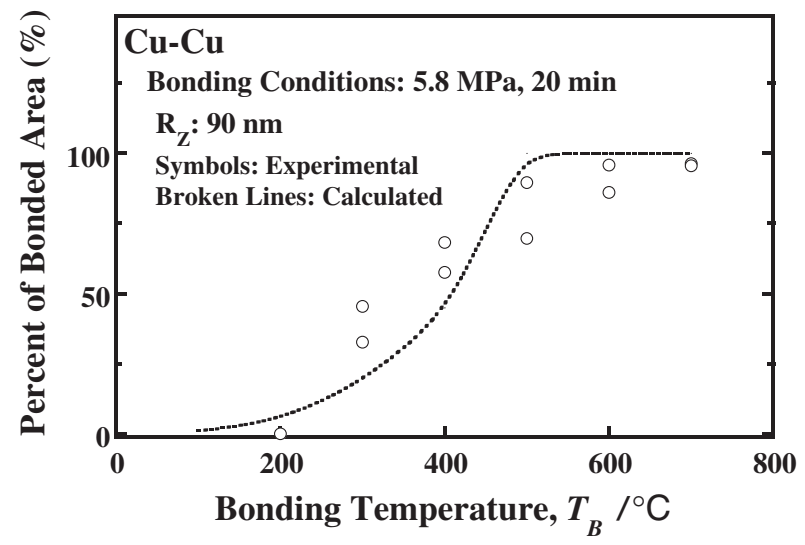

Fig. 6 Comparison between experimental and calculated percent of bonded area for specimen $\mathrm{A}\left(R_{\mathrm{Z}}: 90 \mathrm{~nm}\right)$.

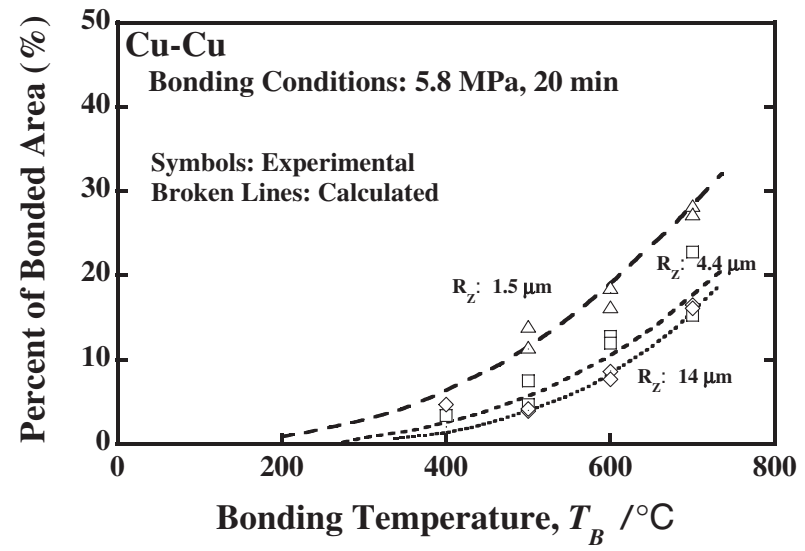

Fig. 7 Comparison between experimental and calculated percent of bonded area for specimen B $\left(R_{\mathrm{Z}}: 1.5 \mu \mathrm{m}\right), \mathrm{C}\left(R_{\mathrm{Z}}: 4.4 \mu \mathrm{m}\right)$ and $\mathrm{D}\left(R_{\mathrm{Z}}\right.$ : $14 \mu \mathrm{m})$.

the bonded interface and with very little deformation of joints.

\subsection{Optimum surface asperities with numerical analysis model}

From the above results, it is clear that the numerical model is applicable to surfaces with a wide range of surface roughness from nanometer to micrometer scales. In this section, the effect of the aspect ratio $H / W$ on the bonded area will be discussed.

Generally, surfaces prepared by lathe machining (shown in Table 2) have a low aspect ratio $(H / W<0.05)$. Here, a bonding process for a specimen with aspect ratio $H / W: 0.025$ (ridge height $H: 0.5 \mu \mathrm{m}$, ridge wavelength $W: 20 \mu \mathrm{m}$ ), is analyzed numerically. The calculated predictions for percent of bonded area and the contributions of the three fundamental mechanisms (plastic deformation, creep deformation and atomic diffusion) are shown in Fig. $8 . \mathrm{S}_{\mathrm{P}}$ is the contribution of plastic deformation, $S_{C}$ is the contribution of creep deformation, and $\mathrm{S}_{\mathrm{D}}$ is the contribution of atomic diffusion. The sum of $S_{P}, S_{C}$ and $S_{D}$ is the total percent of bonded area $\mathrm{S}$. When the bonding temperature is lower than $600^{\circ} \mathrm{C}$, the increase of bonded area is mainly controlled by atomic diffusion, while above $600^{\circ} \mathrm{C}$, the increase of bonded area is

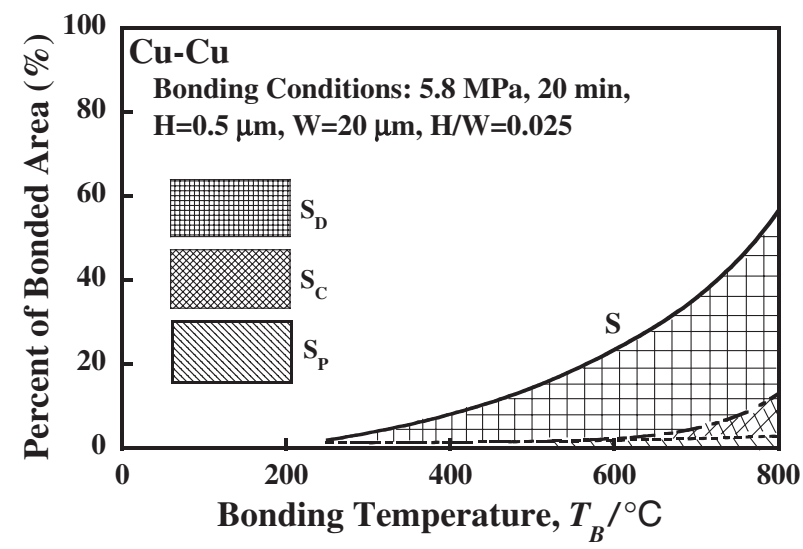

Fig. 8 Relationship between percent of bonded area and bonding temperature for general surfaces with low aspect ratio $H / W=0.025$.

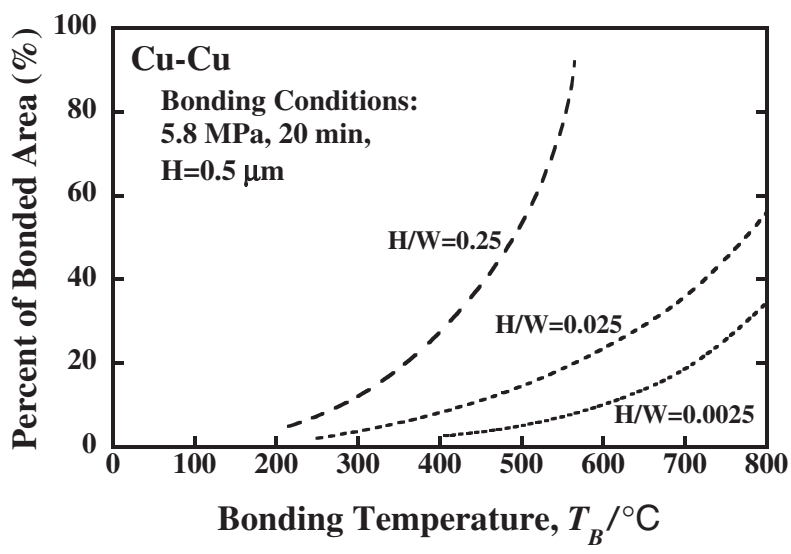

Fig. 9 Relationship between percent of bonded area and bonding temperature for various aspect ratios $H / W$.

mainly controlled by creep deformation.

Next, the effect of aspect ratio $H / W$ on the percent of bonded area is calculated with the ridge height $H$ held constant $(H=0.5 \mu \mathrm{m})$. Figure 9 shows the relationship between percent of bonded area and bonding temperature when the aspect ratio $H / W$ is $0.0025,0.025$ and 0.25 . The percent of bonded area obviously increases with increasing $H / W$. When $H / W$ is 0.25 , full bonding is attained at a temperature lower than $600^{\circ} \mathrm{C}$. In other words, the percent of bonded area increases with decreasing ridge wavelength $W$ even at the same ridge height $H$. The results indicate that contribution of atomic diffusion increases significantly with decreasing ridge wavelength $W$. It is considered that there are more voids formed in the bonding interface with a small ridge wavelength $W$ than with a large $W$, and the volume of individual voids is small for a bonding interface with small ridge wavelength $W$. It is known that a small void has a large surface tension that tends to increase atomic diffusion owing to its small radius of curvature. ${ }^{14)}$

Based on these numerical analysis results, it is clear that increasing the aspect ratio $H / W$ improves atomic diffusion at the interface and accelerates the shrinkage of voids, thereby increasing the bonded area. 
Table 3 Parameters of surface asperities for specimen New B prepared by an improved machining technique, along with those of specimen $\mathrm{B}$.

\begin{tabular}{ccccc}
\hline \multirow{2}{*}{ Samples } & \multicolumn{4}{c}{ Surface Parameters } \\
\cline { 2 - 5 } & $R_{\mathrm{Z}}$ & $H$ & $W$ & $H / W$ \\
\hline B & $1.5 \mu \mathrm{m}$ & $0.9 \mu \mathrm{m}$ & $24 \mu \mathrm{m}$ & 0.04 \\
New B & $0.5 \mu \mathrm{m}$ & $0.5 \mu \mathrm{m}$ & $2.1 \mu \mathrm{m}$ & 0.24 \\
\hline
\end{tabular}

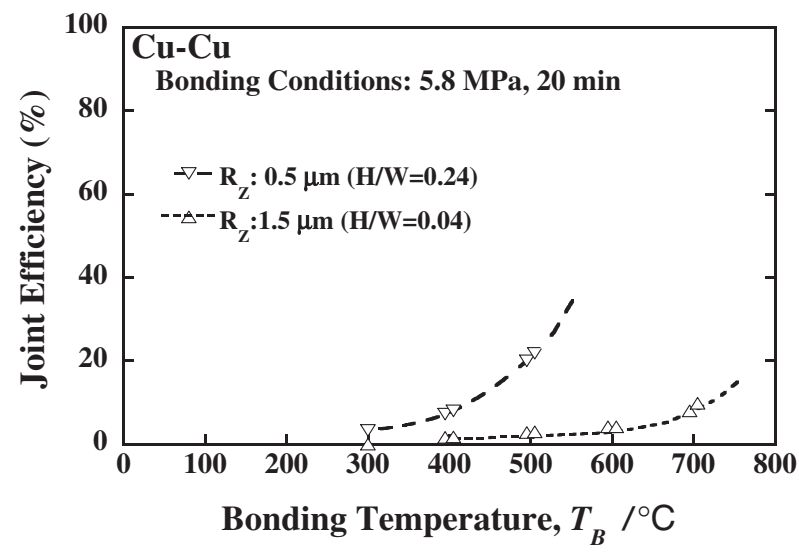

Fig. 10 Effect of aspect ratio $H / W$ on joint efficiency.

\subsection{Effect of aspect ratio $H / W$ on bonded area}

Numerical analysis predicts that a larger aspect ratio $H / W$ (or a small ridge wavelength $W$ ) can increase the bonded area when the ridge width $H$ is constant. In order to validate the effect of the aspect ratio $H / W$ on the bonded area, a surface with small ridge wavelength $W$ was prepared with an improved machining technique. This new specimen has the same order of roughness as specimen B. Table 3 presents the parameters of specimen New B along with those of specimen B.

Diffusion bonding experiments for specimen New B were carried out at a temperature of $300-500^{\circ} \mathrm{C}$. Joint efficiency was measured by the ratio of tensile strength to parent material strength, as obtained from a standard specimen that experienced the same thermal history as the bonded joints. The effect of aspect ratio $H / W$ on joint efficiency is shown in Fig. 10. The joint efficiency was obviously increased for the specimen with a larger aspect ratio $H / W$, though the two specimens were not greatly different in surface roughness.

To obtain the percent of bonded area of specimen New B, the relationship between joint efficiency and percent of bonded area for the previous four kinds of specimens was investigated. Based on the results in Figs. 2, 6 and 7, the relationship between joint efficiency and the percent of bonded area is summarrized in Fig. 11. Regardless of the surface roughness $R_{\mathrm{Z}}$, the joint efficiency is a function of the percent of bonded area. Therefore, it is possible to predict the percent of bonded area of the bonded joints from the joint efficiency. Furthermore, it is clear that the joint efficiency is smaller than the percent of bonded area at almost every bonding temperature. This is thought to be due to inclusions fromed in the bonding interface from oxide films on the faying surface during the diffusion bonding of copper. ${ }^{15)}$ Due to the inclusions, the joint efficiency cannot increase

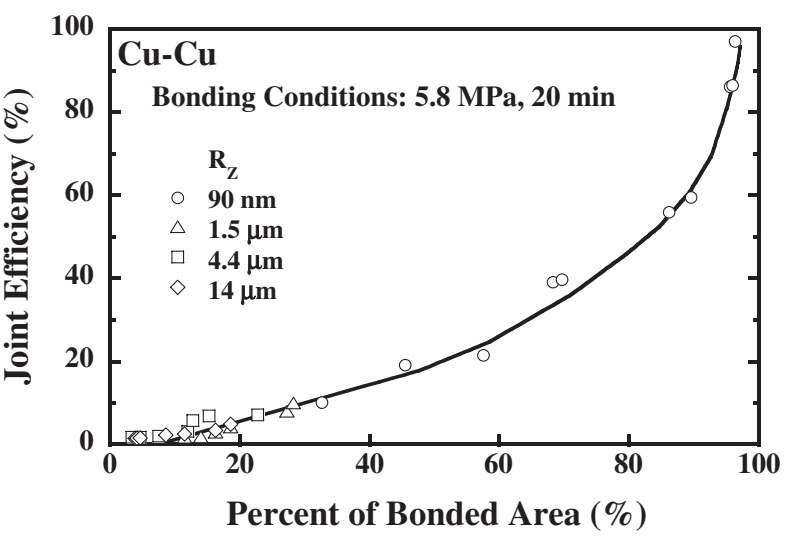

Fig. 11 Relationship between joint efficiency and percent of bonded area for various surfaces.

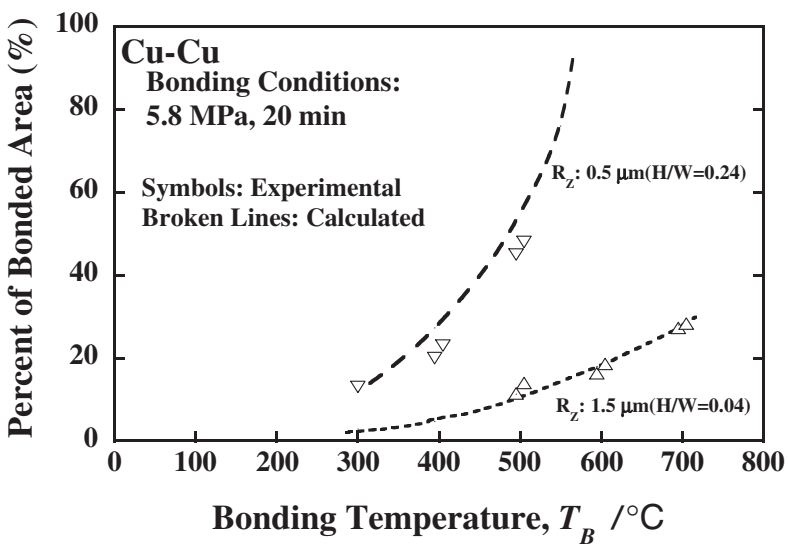

Fig. 12 Comparison between experimental and calculated percent of bonded area for $H / W=0.04$ and 0.24

proportionately with the increase in the percent of bonded area. Based on this relationship, the actual percent of bonded area of specimen New B was obtained. Figure 12 comparison the calculated and observed percent of bonded area for specimens B and New B. Symbols show the actual percent of bonded area, and the calculated results are shown by broken lines. It can be seen that the calculated results are consistent with the actual percent of bonded area.

The above results and discussion demonstrate that the percent of bonded area increases with increasing aspect ratio $H / W$ even if the ridge height $H$ is held constant.

Previous studies of the effect of surface asperity have concentrated mainly on surface roughness $\left(R_{\mathrm{Z}}\right.$ or $\left.R_{\mathrm{a}}\right)$, especially on ridge height $H$. A decrease in $H$ reduces the volumes of voids formed at the bonding interface. The number of atoms required to fill these voids decreases. Therefore specimens with a small ridge height $H$ can be bonded at a lower temperature or in a shorter time.

On the other hand, if the ridge height $H$ is constant, when the ridge wavelength $W$ is reduced (or aspect ratio $H / W$ is increased), the number of voids increases, but the volume of each individual void decreases. The atomic diffusion at the surface and interface accelerates, being controlled by surface tension. Therefore specimens with a larger aspect ratio $H / W$ can be bonded at lower temperature or in less time. 


\section{Conclusions}

The effects of surface asperity (mainly ridge wavelength $W$ and aspect ratio $H / W$ ) on the properties of diffusion bonded joints were investigated. The results obtained are summarized as follows.

(1) Ridge wavelength $W$, as well as ridge height $H$, as parameters describing surface asperity, have a significant effect on the properties of a diffusion bonded joint. The bonded area increases with decreases in $W$ and $H$. Thus decreases of $W$ and $H$ can improve the diffusion bonding process.

(2) If the ridge height $H$ is constant, a larger aspect ratio $H / W$ accelerates atomic diffusion at void surfaces and the bonding interface, facilitates the shrinking of voids and increases the bonded area. Such specimens can be bonded at a lower temperature or in a shorter time.

(3) The bonded area of surface prepared by lathe machining can be predicted using numerical analysis.

\section{Acknowledgements}

The authors would like to thank Dr. Yoshisato Funahashi of the High Energy Accelerator Research Organization for his contribution of materials and specimen machining, and Prof. Kunio Takahashi of the Graduate School of Science and
Engineering, Tokyo Institute of Technology for providing the numerical analysis program.

\section{REFERENCES}

1) A. Wang, O. Ohashi and N. Yamaguchi: Mater. Sci. Forum 449-452 (2004) 901-904.

2) A. Wang, O. Ohashi, M. Aoki, N. Yamaguchi, Y. Higashi and N. Hitomi: Nucl. Inst. Meth. B206 (2003) 219-223.

3) M. J. Cox, M. J. Kim and R. W. Carpenter: Metall. Mater. Trans. A33 (2002) 437-442.

4) T. Suga, Y. Takahashi, H. Takagi, B. Gibbesch and G. Elssner: Acta Metal. Mater. 40 (1992) 133-137.

5) H. Takagi, R. Maeda, N. Hosoda and T. Suga: Jpn. J. Appl. Phys. 38 (1999) 1589-1594.

6) O. Ohashi and T. Hashimoto: J. Jpn. Weld. Soc. 45 (1976) 485-491.

7) B. Derby and E. R. Wallach: Met. Sci. 16 (1982) 49-56.

8) J. Pilling, D. W. Livesey, J. B. Hawkyard and N. Ridey: Met. Sci. 18 (1984) 117-122.

9) Z. X. Guo and N. Ridley: Met. Sci. Tech. 3 (1987) 945-952.

10) K. Nishiguchi and Y. Takahashi: J. Jpn. Weld. Sco. 3 (1985) 303-315.

11) Y. Takahashi, F. Ueno and K. Nishiguchi: Acta Metall. 36 (1988) 3007-3018.

12) Y. Takahashi and K. Inoue: J. Mater. Sci. Technol. 8 (1992) 953-964.

13) A. Wang, O. Ohashi, N. Yamaguchi, Y. Higashi, N. Hitomi and K. Takahashi: Trans. Mater. Res. Soc. Jpn. 27 (2002) 739-742.

14) Y. Takahashi: J. Jpn. Weld. Sco. 64 (1995) 289-294.

15) A. Wang, O. Ohashi, N. Yamaguchi, G. Xie, M. Song, K. Furuya, Y. Higashi and N. Hitomi: J. Electron Microsco. 53 (2004) 157-161. 